\title{
8
}
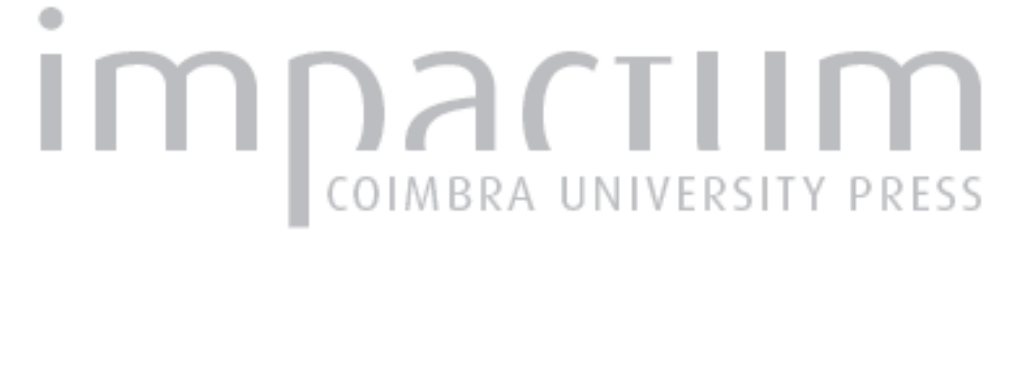

\section{Patologia infecciosa ocupacional em bombeiros: os Centers for Disease Control and Prevention (CDC-USA 2016) face ao Decreto Regulamentar Português no 76/2007}

\author{
Autor(es): $\quad$ Leão, Rui Ponce; Campos, Paulo; Gandra, Sara; Bandeira, Romero
}

Publicado por: Associação Portuguesa de Riscos, Prevenção e Segurança; Imprensa

URL

persistente:

da Universidade de Coimbra

DOI: DOI:https://doi.org/10.14195/1647-7723_23_16

Accessed : $\quad$ 26-Apr-2023 11:32:28

A navegação consulta e descarregamento dos títulos inseridos nas Bibliotecas Digitais UC Digitalis, UC Pombalina e UC Impactum, pressupõem a aceitação plena e sem reservas dos Termos e Condições de Uso destas Bibliotecas Digitais, disponíveis em https://digitalis.uc.pt/pt-pt/termos.

Conforme exposto nos referidos Termos e Condições de Uso, o descarregamento de títulos de acesso restrito requer uma licença válida de autorização devendo o utilizador aceder ao(s) documento(s) a partir de um endereço de IP da instituição detentora da supramencionada licença.

Ao utilizador é apenas permitido o descarregamento para uso pessoal, pelo que o emprego do(s) título(s) descarregado(s) para outro fim, designadamente comercial, carece de autorização do respetivo autor ou editor da obra.

Na medida em que todas as obras da UC Digitalis se encontram protegidas pelo Código do Direito de Autor e Direitos Conexos e demais legislação aplicável, toda a cópia, parcial ou total, deste documento, nos casos em que é legalmente admitida, deverá conter ou fazer-se acompanhar por este aviso.

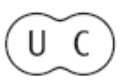




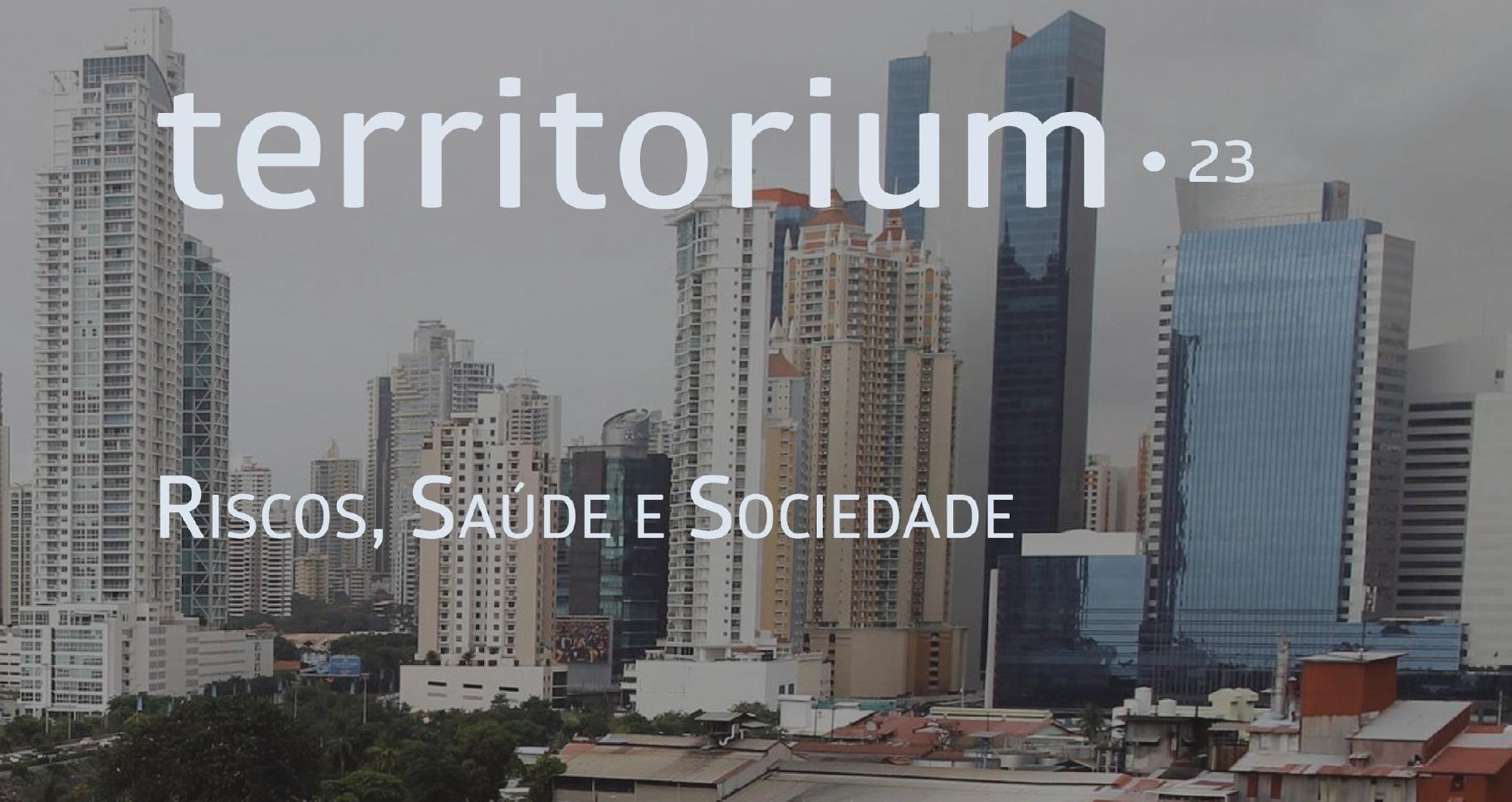

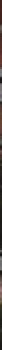

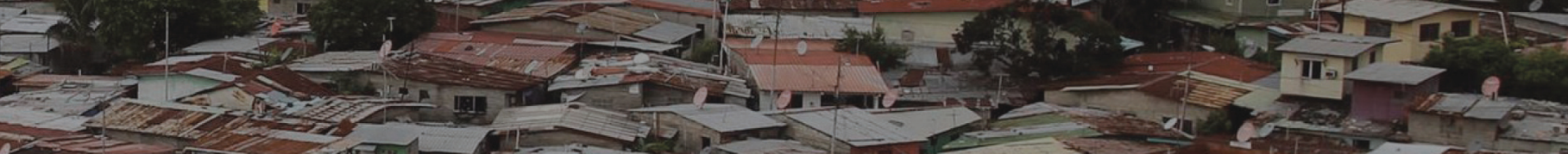

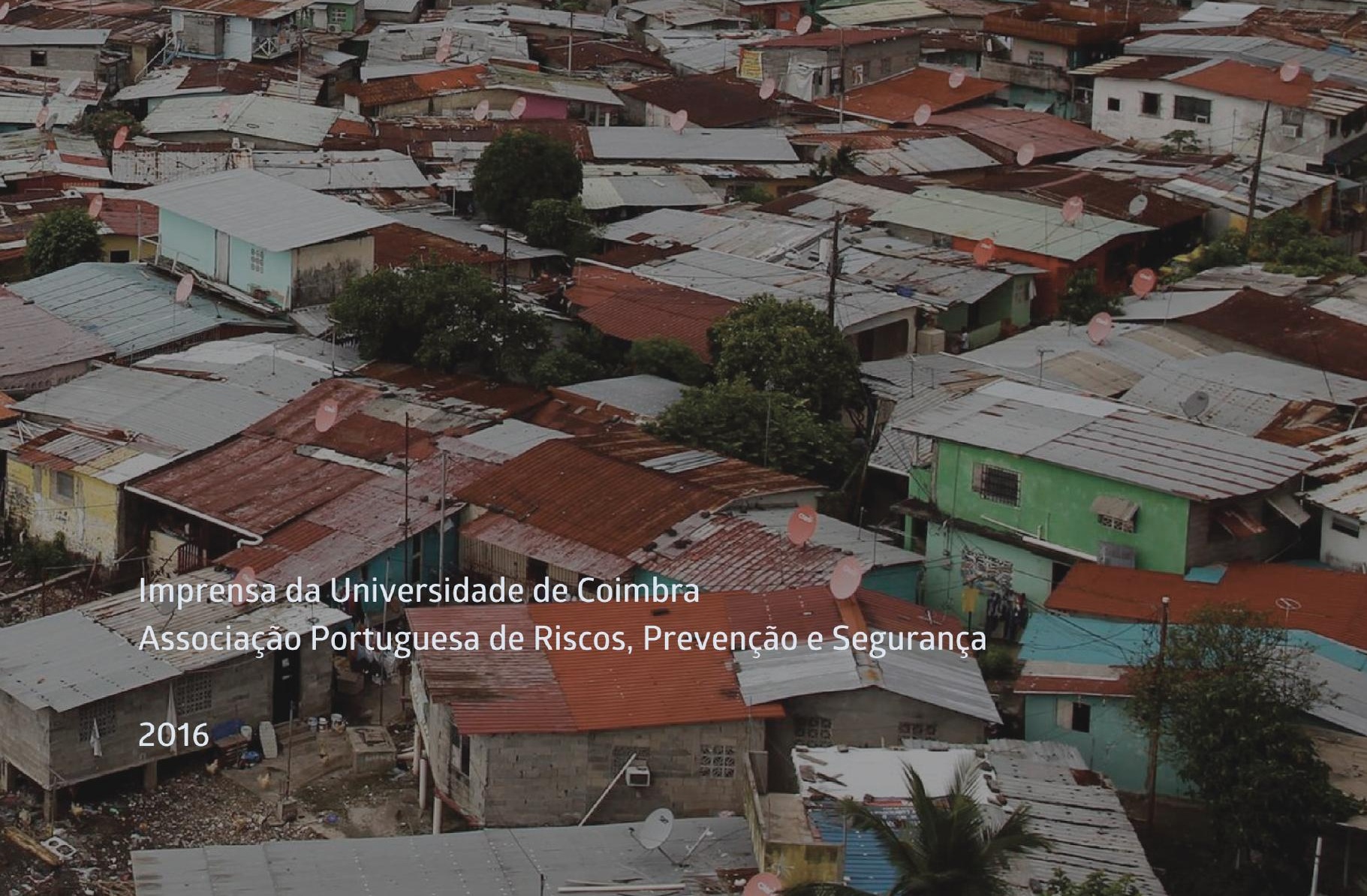




\section{PATOLOGIA INFECCIOSA OCUPACIONAL EM BOMBEIROS: OS CENTERS FOR DISEASE CONTROL AND PREVENTION (CDC - USA 2016) FACE AO DECRETO REGULAMENTAR PORTUGUÊS N $76 / 2007^{*}$}

\section{OCCUPATIONAL INFECTIOUS PATHOLOGY IN FIREFIGHTERS: \\ THE CENTERS FOR DISEASE CONTROL AND PREVENTION (CDC-USA) 2016 REGARDING THE PORTUGUESE REGULATORY DECREE No 76/2007}

\author{
Rui Ponce Leão \\ Hospital de Santa Maria do Porto \\ Consultor da UEIFIS AHCBVSPCova \\ ruipleao@gmail.com \\ Paulo Campos
}

TCor Médico, U.S. II - VN Gaia/Exército Português Consultor da UEIFIS AHCBVSPCova pacampos@netcabo.pt

\author{
Sara Gandra \\ CHP-HSA \\ Consultora da UEIFIS AHCBVSPCova \\ saragandra@gmail.com \\ Romero Bandeira
}

Dir. Curso de Medicina de Catástrofe, ICBAS, Univ. Porto Director da UEIFIS AHCBVSPCova hmedcat@icbas.up.pt

\section{RESUMO}

Os Bombeiros têm, frequentemente, contacto com doentes portadores de patologia infecto-contagiosa, bem como com animais sãos ou doentes, cadáveres e, eventualmente, outras situações onde possam co-existir agentes causadores de doenças. Neste sentido aborda-se o conteúdo do DR Português 76/2007 comparando-o com o que os CDC-USA 2016 explanam sobre a mesma matéria. Dada a relevância da mesma chama-se a atenção para lacunas existentes, mesmo no contexto dos CDC, no sentido da necessidade da premente actualização da Legislação Portuguesa neste âmbito.

Palavras-chave: Patologia ocupacional, infecção, Bombeiros, CDC, decreto-regulamentar.

\section{ABSTRACT}

Firefighters often have contact with patients with infectious disease as well as healthy or sick animals, dead bodies and possibly other situations where can co-exist disease-causing agents. In this sense it addresses the contents of DR Portuguese 76/2007 comparing it to what the CDC-USA 2016 expounds on the same subject. Given the importance of the theme we enhance, even in the context of the CDC, the need of urgent update of the Portuguese legislation in this area.

Keywords: Occupational disease, infection, firefighters, CDC, regulatory decree.

\section{Introdução}

O conceito de Patologia Ocupacional, num sentido lato, pode ser aplicado aos diversos tipos de Bombeiros, nomeadamente Profissionais e Voluntários, sendo utilizável, para tal, o Decreto Regulamentar n. ${ }^{\circ}$ 76/2007 (DR 76/2007), de 17 de Julho, do Ministério do Trabalho e da Solidariedade, que actualiza o Decreto Regulamentar n. ${ }^{\circ}$ 6/2001, que contém a Lista das Doenças Profissionais e o respectivo Índice Codificado.

Assim sendo, o propósito do artigo é simples. Fundamentalmente procura-se chamar a atenção para a falência dos possíveis objectivos científicos, do citado Decreto com as consequentes profundas repercussões operacionais. Desde a univítima que pode causar contágio ao interventor (Sikorski et al., 2012), podemos extrapolar, por exemplo, uma situação limite de socorro, como no caso de uma pandemia que poderá configurar uma situação de megacatástrofe no espaço e no tempo; esta, obviamente envolvendo multivítimas, das quais podem fazer parte integrante as equipas de socorro face à sua exposição no terreno, inclusivamente podendo levar à sua neutralização (OSHA 2016 a).

Não é nosso propósito explanar uma metodologia analítica com a finalidade de predizer a alteração ao DR 76/2007, mas sim, dissecar, ainda que sumariamente, as suas deficiências face a informação científica actual, existente quer em Portugal, quer no Estrangeiro, contida em suporte de papel ou digital e perfeitamente acessível a qualquer investigador ou especialista interessados nesta área.

* O texto desta nota corresponde a uma comunicação apresentada no I Seminário da Rede Incêndios-Solo e I Simpósio Ibero-Afro-Americano de Riscos, tendo sido submetido em 30-11-2015, sujeito a revisão por pares a 18-03-2016 e aceite para publicação em 30-06-2016.

Esta nota é parte integrante da Revista Territorium, n. ${ }^{\circ} 23,2016,{ }^{\circ}$ RIscos, ISSN: 0872-8941. 
Citemos H Julien (2013):

"[...] A única verdadeira ciência é o conhecimento dos factos. A verdade sempre vem do terreno. É o compromisso operacional num acidente catastrófico de efeito limitado ou numa catástrofe de grandes proporções, que permite o progresso. Assim são depositados lentamente estratos de conhecimento que constituíram a medicina de catástrofe [...]".

OS CDC (http: / / www.cdc.gov/HAl/organisms/organisms. html) apresentaM sob o título Healthcare-Associated Infections (HAls), Diseases and Organisms in Healthcare Settings, uma lista onde constam vários agentes que não se encontram no DR 76/2007.

Contudo, as actividades dos Bombeiros - sendo estes uma das pedras angulares do Sistema Integrado de Emergência Médica (SIEM) - podem levar a situações de risco, devido ao seu contacto com agentes biológicos patogénicos que devem ser conhecidos e evidenciados.

Nesta ordem de ideias o SIEM (2013) dispõe hoje, de três Centrais de Comunicações de Doentes Urgentes (CODU), a funcionar numa tipologia de CODU Nacional. Dispõe ainda de meios medicalizados e não medicalizados, operados directamente pelo INEM ou, na sua grande maioria, através de protocolo com outras entidades (Corpos de Bombeiros, Cruz Vermelha Portuguesa/CVP e Hospitais): 43 VMER (Viatura Médica de Emergência e Reanimação), tripuladas por um médico e um enfermeiro, 40 SIV (Ambulância de Suporte Imediato de Vida), tripuladas por um enfermeiro e um técnico de emergência, 56 AEM (Ambulância de Emergência Médica), tripuladas por dois técnicos de emergência, 8 MEM (Motociclo de Emergência Médica), tripulados por um técnico de emergência, 300 postos PEM (Ambulância que constitui protocolo 'Posto de Emergência Médica' operada por Corpo de Bombeiros ou CVP), tripuladas por técnicos de ambulância de socorro, 157 postos de reserva (Protocolos 'Posto de Reserva' operada por Corpo de Bombeiros ou (VP), que corresponde a, pelo menos, uma viatura ambulância e tripulação por protocolo), 37 NINEM (Ambulância sem protocolo INEM), activada com cariz ocasional e por necessidade, operada por Corpo de Bombeiros ou CVP, 5 Helicópteros SHEM (Serviço de Helicópteros de Emergência Médica), de cuja tripulação fazem parte um médico e um enfermeiro, 4 TIP (Ambulância de Transporte Inter-hospitalar Pediátrico), tripuladas por um médico, um enfermeiro e um técnico de emergência e 4 UMIPE (Unidade Móvel de Intervenção Psicológica de Emergência), tripuladas por um psicólogo e um técnico de emergência, num total de 654 meios disponíveis para o cidadão. Em acréscimo e reserva do sistema, existem ainda numerosas ambulâncias disponíveis nos Corpos de Bombeiros que poderão ser activadas através dos CDOS (Comando Distrital de Operações de Socorro) da ANPC (Autoridade Nacional de Proteção Civil).
Assim sendo, é da maior relevância estarmos alertados e cientificamente consciencializados no que concerne a patologias ou agentes patogénicos que podem afectar os Bombeiros, quer Profissionais quer Voluntários ou ainda outros interventores, como já se referiu.

\section{Do Decreto Regulamentar Português n 76/2007 aos CDC}

Em termos conceptuais e conforme Antunes (2015) nos transmite, com base nas definições dos CDC, "Definese infecção como uma reação adversa, localizada ou sistémica, à presença de um agente infeccioso ou às suas toxinas".

Infecção da comunidade é a infecção diagnosticada nas primeiras $48 \mathrm{~h}$ após a admissão e associada a cuidados de saúde, a que surge no período de 48 horas ou mais após a admissão hospitalar e que não se encontrava em incubação no momento da admissão.

Define-se colonização como a presença de microrganismos na pele, mucosas, feridas, excreções ou secreções sem sinais ou sintomas adversos e inflamação como a resposta tecidular à lesão ou estimulação por agentes não infecciosos.

De acordo com o mesmo autor, resumimos a estratificação da gravidade, que pode ser assim estabelecida:

- $\quad$ SIRS - Sistemic Inflamatory Response Syndrome

- $\quad$ Sépsis

- Hipotensão induzida pela sepsis

- Hipoperfusão induzida pela sepsis

- $\quad$ Sepsis grave

- Choque séptico.

No DR 76/2007 são enumeradas as doenças infecciosas e parasitárias que podem ser consideradas Doença Profissional. No mesmo documento e do código 51.01 ao 52.07 dão explicitadas as doenças infecciosas (bacterianas e víricas) de acordo com a TABELA I.

Contudo, face à realidade da fácil circulação não controlada de pessoas e outros seres vivos e de bens, podem surgir outros agentes, não descritos no DR $76 / 2007$.

Assim, de acordo com os CDC chamamos a atenção para a TABELA II.

Comparando o conteúdo do Decreto Regulamentar n. ${ }^{\circ} 76 / 2007$ sobre Doenças infecciosas com a lista dos CDC - Healthcare-Associated Infections (HAls), Diseases and Organisms in Healthcare Settings - Centers for Disease Control and Prevention (CDC) verifica-se que os seguintes agentes só se encontram indicados nos CDC: Acinetobacter, Burkholderia cepacia, Clostridium 
TABELA I - DR 76/2007 - Doenças infecciosas.

TABLE I - RD 76/2007 - Infectious Diseases.

\begin{tabular}{|l|l|l|}
\hline \multicolumn{2}{|c|}{51 - Causadas por bactérias e afins: } & $\mathbf{5 2}$ - Causadas por vírus: \\
\hline 51.01 - Tétano. & 51.13 - Sífilis cutânea. & 52.01 - Raiva. \\
\hline 51.02 - Bruceloses. & $51.14-$ Infecções por enterobacteriáceas & 52.02 - Hepatites víricas. \\
\hline 51.03 - Tuberculoses. & 51.15 - Salmoneloses. & 52.03 - Poliomielite \\
\hline 51.04 - Estreptococia por Streptococcus suis & 51.16 - Listeriose. & 52.04 - Varicela. \\
\hline 51.05 - Carbúnculo. & 51.17 - Erisipelóide & 52.05 - Rubéola. \\
\hline 51.06 - Rickttsioses. & 51.18 - Tularémia. & 52.06 - Sarampo. \\
\hline 51.07 - Meningococias. & $51.19-$ Tracoma ocular. & 52.07 - Parotidite \\
\hline 51.08 - Estreptococias (outras). & $51.20-$ Ornitose-psitacose. & \\
\hline 51.09 - Difteria. & $51.21-$ Doença de Lyme. & \\
\hline 51.10 - Estafilococias. & 51.22 - Pasteurolose. & \\
\hline 51.11 - Shigeloses. & 51.23 - Leptospirose. & \\
\hline 51.12 - Infecções por Pseudomonas. & & \\
\hline
\end{tabular}

TABELA II - Infecções associadas a cuidados de saúde (IACS), doenças e organismos em ambientes de saúde.

TABLE II - Healthcare-Associated Infections (HAls), Diseases and Organisms in Healthcare Settings.

\begin{tabular}{|l|l|}
\hline Acinetobacter & Klebsiella \\
\hline Burkholderia cepacia & Methicillin-resistant Staphylococcus aureus \\
\hline Clostridium difficile & Mycobacterium abscessus \\
\hline Clostridium sordellii & Norovirus \\
\hline Enterobacteriaceae (carbapenem-resistentes) & Pseudomonas aeruginosa \\
\hline Gram-negative bacteria & Staphylococcus aureus \\
\hline Hepatitis & Tuberculosis (TB) \\
\hline Human Immunodeficiency Virus (HIV) & $\begin{array}{l}\text { Vancomycin-intermediate Staphylococcus aureus } e \\
\text { Vancomycin-resistant Staphylococcus aureus }\end{array}$ \\
\hline Influenza & Vancomycin-resistant Enterococci (VRE) \\
\hline
\end{tabular}

difficile, Clostridium sordellii, Mycobacterium abscessus, Norovírus, Virus da Imunodeficiência Humana, Vírus da Influenza (gripe).

Acinetobacter - bactérias comumente encontradas no solo e na água, sendo que o Acinetobacter baumannii é responsável por cerca de $80 \%$ das infecções relatadas. Aquando de surtos de Acinetobacter as infecções normalmente ocorrem em unidades de terapia intensiva e instalações de saúde onde se encontram doentes graves. Pode provocar diversas doenças, nomeadamente pneumonia e também pode "colonizar" ou viver num paciente sem causar infecção ou sintomas, especialmente em traqueostomia ou feridas abertas.
O Acinetobacter pode viver na pele e pode sobreviver no ambiente por várias semanas. Deve existir muita atenção com procedimentos de controlo de infecção, tais como a higiene das mãos e ambiente para reduzir o risco de transmissão. De acordo com Oliveira (2015) resistem à dissecação, aderem às superfícies e equipamentos formando biofilme e sobrevivem à dissecação durante várias semanas.

Burkholderia cepacia (b. cepacia) - conforme nos transmitem os CDC (2016) e Schwartz (2016) é o nome de um grupo ou "complexo" de bactérias que podem ser encontrados no solo e na água. $B$. cepacia costumam ser resistentes aos antibióticos 
comuns. Têm pouco risco para pessoas saudáveis. Podem não existir sintomas, mas, eventualmente, surgirem infecções respiratórias graves.

De acordo com os CDC (2016) a B. cepacia pode ser transmitida a pessoas susceptíveis por: contato interpessoal, contato com superfícies contaminadas e exposição a $B$. cepacia no meio ambiente.

Clostridium difficile - segundo Schwartz (2016) trata-se de uma bactéria que provoca inflamação do cólon, com diarreia e febre. Normalmente ocorre de 7-10 dias de tratamento com antibióticos ou várias semanas após a conclusão do tratamento; um início abrupto de diarreia, eventualmente com sangue e febre pode ocorrer. Na acção dos interventores no socorro é da maior importância cumprir escrupulosamente os princípios de higiene.

Deve ser realçada a diferença entre indivíduo com colonização por Clostridium difficile e infectado com Clostridium difficile (Antunes 2015).

Em situações de suspeita ou doença confirmada por Clostridium difficile devem utilizar-se luvas ao entrar no quarto do doente e no contacto com este; após retirar as luvas as mãos devem ser adequadamente lavadas, porque a utilização de desinfecção com álcool não mata os esporos - a lavagem com água e sabão é mais eficaz. As luvas e outro material de protecção utilizado devem ser rigorosamente colocados num "saco branco" para eliminação.

Clostridium sordellii - igualmente de acordo com os CDC (2016) e Schwartz (2016), os sintomas de infecção provocados por este microorganismo incluem náuseas, vómitos, diarreia e dor abdominal às vezes sem febre. Síndrome do Choque Tóxico por Clostridium sordellii, de início brusco após aborto médico, com dor abdominal, sem febre, com taquicardia, hipotensão grave, edema. As medidas preventivas a tomar são, fundamentalmente, as preconizadas para o contacto com a estirpe bacteriológica anteriormente citada.

Mycobacterium abscessus - com base nas mesmas fontes, CDC (2016) e Schwartz (2016), é longinquamente aparentada com os mycobacterium causadores da tuberculose e da lepra, aparece na água, solo e poeira, podendo contaminar medicamentos e produtos, incluindo dispositivos médicos. Podem causar diversas infeções mais frequentemente da pele e do tecido celular sub-cutâneo, assim como também infecções pulmonares em doentes com patologia pulmonar crónica.
Quem contactar com local ou material infectado deve lavar as mãos cuidadosamente com água e sabão. Os pacientes devem seguir todas as instruções dadas pelo seu médico após qualquer cirurgia ou procedimento médico. Evitar actos/ procedimento de não profissionais.

Norovírus - causam gastroenterite no ser humano, com início agudo de vómito e diarreia, que rapidamente cura. Contudo crianças pequenas, pessoas com outras patologias e idosos podem ter uma infecção mais grave ou prolongada.

Não estão indicados antibióticos; a disseminação é rápida, nomeadamente em instalações de saúde, creches, escolas, centros de dia, lares de $3^{a}$ idade, retiros/concentrações desportivas ou outras, eventos tais como festivais. Os sintomas incluiem náuseas, vómitos, predominantemente em adultos e diarreia sobretudo nas crianças. Quando não existe ingestão adequada de líquidos para compensar os perdidos pelos vómitos, diarreia ou transpiração, pode surgir desidratação; esta cursa, entre outra sintomatologia, com diminuição da micção, boca e garganta secas, tonturas ao levantar, etc, necessitando de correcção hidroelectrolítica de acordo com os CDC (2016) e Kelly e Shandera (2016).

Os norovírus são identificáveis nas fezes e vómito dos infectados. O contacto directo com alguém infectado, comer alimentos ou beber líquidos contaminados, contactar com superfícies ou objectos contaminados pode dar origem à infecção.

Evitar o contacto do doente com outras pessoas não contaminadas, manter a higiene das mãos, usar vestuário e luvas adequadas, limpar e desinfectar superfícies e equipamentos em que o doente, vómito ou fezes tenham contactado, retirar e lavar as roupas contaminadas ou roupa de cama. Quando um trabalhador da saúde tem sintomas compatíveis com o norovírus, deve ser afastado da actividade até à cura.

Vírus da Gripe (Influenza) - muito frequente, com números por vezes alarmantes, anualmente, apesar de existir vacina. A Organização Mundial de Saúde (OMS 2016a) acompanha e divulga a atividade da gripe a nível mundial publicando actualização dos dados de duas em duas semanas, tendo como suporte os dados de atualização sobre a gripe.

Influenza na Interface Homem-Animal (HAI) - de acordo com OMS (2016b) “Os vírus da gripe em circulação em animais representam ameaças para a saúde humana. Os seres humanos podem 
ficar doentes quando infectados com vírus de origem animal, tais como o vírus da gripe aviária, subtipos H5N1 e H9N2 e suínos, subtipos do vírus da gripe H1N1 e H3N2. O principal fator de risco para a infecção humana parece ser a exposição directa ou indirecta a animais vivos ou mortos infectados ou a ambientes contaminados."

Vírus da imunodeficiência humana (HIV) - pode originar Síndrome de Imunodeficiência Adquirida (SIDA), destruindo células T CD4+ do sangue, fundamentais para a defesa do organismo humano, pelo que as vítimas são mais facilmente atingidas por outras doenças infecto-contagiosas e cancro.

Segundo a OMS (2016c) a comunidade internacional está empenhada em acabar com a epidemia de SIDA até 2030. Na Agenda para 2030 sobre Desenvolvimento Sustentável, adoptada pela Assembleia Geral das Nações Unidas em Setembro de 2015 foram estabelecidas metas a serem cumpridas até 2020, propondo estratégias para atingir esses objectivos, quer quanto aos países, quer quanto à própria OMS.

As normas profilácticas e de protecção individual e colectiva estão em permanente actualização no sítio da Direcção Geral de Saúde de Portugal.

\section{Agentes Patogénicos não Evidenciados no DR 76/2007 e nos CDC}

Porém, sem querermos ser exaustivos e obviamente a titulo de exemplo, entendemos dever elencar nas alíneas a), b), e c) alguns factores de risco e agentes patogénicos, procurando chamar a atenção para a necessidade de uma actualização cientifica sistemática face às inúmeras fontes de informação disponíveis: a) Assim devemos evidenciar o que Cardoso e Polónia (2015), nos apresentam na TABELA III, excerto da original publicada integralmente no Manual Pratico de Utilização de Anti-Infecciosos;

b) Entendemos dever igualmente, chamar a atenção de que a circulação de pessoas, animais, plantas e objectos pode fazer com que sejam importadas patologias de outros locais no Planeta. Por exemplo a Febre da Mordedura de Rato que, sendo pouco comum, pode ser causada pelo treponema Spirillum minus originário da Asia (Philip 2016), ou pelo Streptobacillus moniliformis originário da América do Norte, podendo ser transmitida aos seres humanos, nomeadamente em zonas infestadas de ratos, a possuidores de ratos de estimação ou a trabalhadores de laboratórios

Outro tipo de patologia que se encontra em franca evidência nos últimos anos são as doenças pelos Vírus Ébola, conforme a realidade tem demonstrado, por exemplo, através dos casos de agentes de Saúde mortos por Ébola noutros países.

c) Na actual República Democrática do Congo, perto do rio Ébola, foi descoberto o vírus em 1976, mas têm surgido casos noutros países. Face aos estudos existentes (2016-04-01) parece ser de origem animal sendo os morcegos o reservatório mais provável.

A doença pode ser adquirida por contacto directo (fissuras/cortes na pele e membranas mucosas, nomeadamente olhos, nariz ou boca), contacto com sangue ou fluidos corporais tais como a urina, saliva, suor, fezes, vómito, leite materno, e esperma de infectado ou morto por Ébola, humano ou não, bem como objectos (bisturis,

TABela III -. Factores de Risco e Agentes Patogénicos

TABLE III - Risk factors and Pathogenic Agent

\begin{tabular}{|l|l|}
\hline \multicolumn{1}{|c|}{ Factor de Risco } & \multicolumn{1}{c|}{ Patogénicos } \\
\hline Mordedura Humana & Flora oral, incluindo Eikenella corrodens \\
\hline Mordedura de Gato & Pasteurella multocida \\
\hline Mordedura de Cão & Capnocytophaga canimorsu, Pasteurella multocida \\
\hline Mordedura de Rato & Streptobacillus moniliformis \\
\hline Contacto com Répteis & Salmonella spp \\
\hline Contacto com Outros Animais & $\begin{array}{l}\text { Campylobacter spp, Bartonella henselae, Francisella tularensis, Bacillus } \\
\text { anthracis, Yersinia pestis }\end{array}$ \\
\hline Aquisição em Ambientes Aquáticos & $\begin{array}{l}\text { Aeromonas hydrophila, Vibrio vulnificus, Mycobacterium marinum, } \\
\text { Pseudomonas aeruginosa, Salmonella spp }\end{array}$ \\
\hline
\end{tabular}


pinças, agulhas e seringas, etc.) contaminados com fluidos corporais de doente com Ébola ou falecido por Ébola, bem como por morcegos infectados.

A Doença Ébola (já designado por Febre Hemorrágica Ébola) é rara e mortal, originada por estirpes do vírus Ébola que atingem primatas (humanos e não humanos).

Pertencem à família Filoviridae, género Ebolavirus. Estão identificadas cinco espécies, das quais quatro sabemos causarem doença: Zaire ebolavirus, Sudan ebolavirus; Taï Forest ebolavirus (ex Costa do Marfim ebolavirus) e Bundibugyo ebolavirus; o Reston ebolavirus parece, até agora, só ser causa de doença em primatas não humanos.

O contágio entre seres humanos pode originar grande disseminação. Comer ou tocar em animais infectados, nomeadamente outros primatas, pode levar ao contágio, como muito bem expressaram Savio e Coste-Savio (2015).

Os trabalhadores da Saúde, de acordo com a Orientação n 013/2015 da Direcção Geral de Saúde e que cuidam de pacientes com Ébola, assim como familiares e amigos em contacto próximo com esses pacientes Ébola têm maior risco de adoecer, pois pode vir a surgir contacto com sangue ou fluidos corporais infectados. Para além de médicos e enfermeiros, também Bombeiros, tripulantes de ambulâncias, pessoal do INEM e pessoal dos serviços auxiliares de instituições de saúde, cuidadores de roupas pessoais ou de cama, macas, ambulâncias, hotéis ou outros locais onde possam ter pernoitado ou tido relações sexuais, tanatórios, funcionários de agências funerárias e coveiros podem estar em risco. Mobilização, reanimação, transporte e entrega de doente ou falecido por Ébola, bem como material que com ele tenha estado em contacto, por exemplo em operações de desencarceramento ou salvamento em afogamento ou quase afogamento, podem levar à transmissão dos Ébola. A taxa de mortalidade é de cerca de $50 \%$, tendo anteriormente variado de $25 \%$ a $90 \%$.

Os CDC e a Direcção Geral de Saúde têm disponíveis instruções sobre equipamentos de proteção individual adequados quanto à sua colocação, retirada e eliminação.

\section{Isolamento}

O isolamento não deve ser descurado; em termos de súmula Fernandes et al. (2015), expressam os seguintes elementos, sobre o conceito de isolamento que definem como: "Isolamento é o estabelecimento de barreiras físicas para limitar a transmissão de agentes infecciosos: no mesmo doente entre diferentes locais anatómicos; entre doentes; entre doentes e prestadores de cuidados e entre prestadores de cuidados e doentes" a considerar aplicável ao caso em estudo. Além do exposto, os aludidos autores expendem quanto ao isolamento de contenção o que se encontra expresso na tabela seguinte, excerto da original publicada integralmente no Manual Pratico de Utilização de Anti-Infecciosos (TABELA III).

\section{Reflexões Conclusivas}

Em Portugal, o socorro Extra-Hospitalar encontra-se integrado no SIEM, do qual fazem parte preponderante e muitíssimas vezes como primeiros interventores os Bombeiros, na medida em que os postos de Emergência Médica sediados nos quarteis dos CB's aliados aos Postos de Reserva para além de guarnições e viaturas não integradas nos PEM ou PR e que muitíssimas vezes actuam no terreno a fim de fazerem face às urgências Extra-Hospitalares.

Assim sendo, os Bombeiros, designadamente os Voluntários que são a grandíssima parte dos Bombeiros Portugueses, veem-se confrontados com situações em que os mesmos podem pôr em perigo não só a sua integridade física mas também a sua saúde pessoal, quer psíquica, quer somática designadamente no âmbito de doenças do foro infecto-contagioso (OSHA 2016 b).

Nesta ordem de ideias torna-se absolutamente necessário e extremamente pertinente que seja feita uma análise criteriosa e tanto quanto possível alargada com a finalidade de detectar patologia daquele tipo no sentido duma avaliação e monitorização clínica tendente a uma optimização na normalização da situação clínica.

o Clínico e o Perito Médico na área da Saúde Ocupacional necessitam estar alerta relativamente aos novos dados da Investigação, a nível Nacional e Internacional, relativamente a novas Patologias, quer do ponto de vista

TABELA IV - Isolamento.

TABLE IV - Isolation.

De contenção

Presença ou suspeita de infecção/colonização
Para prevenir a transmissão de microorganismos patogénicos de um doente para os outros e/ou para profissionais e ambiente.

Quarto com pressão negativa - aerossóis

Unidade sem diferencial de pressão- gotícula ou contacto 
Clínico e Terapêutico, quer do ponto de vista MédicoLegal, Pericial e Tanatológico, evitando considerar ser Patologia Não Ocupacional aquela que deve ser real e iniludivelmente considerada Patologia Ocupacional.

\section{Bibliografia}

Antunes, R. (2015). Definição de colonização, infecção e estratificação de gravidade. In: Aragão I, Vasconcelos C (eds) Manual Prático de Utilização de Anti-Infecciosos, $2^{\mathrm{a}}$ ed, Hospital de Santo António, Porto.

Cardoso, T., Polónia J. (2015). Infecções da pele e tecidos moles. In: Aragão I, Vasconcelos C (eds) - Manual Prático de Utilização de AntiInfecciosos, $2^{\text {a }}$ ed, Hospital de Santo António, Porto.

Fernandes, A., Rodrigues P., Mota M. (2015). Tipos de Transmissão da infecção e precauções de isolamento. In: Aragão I, Vasconcelos C (eds) Manual Prático de Utilização de Anti-Infecciosos, $2^{\mathrm{a}}$ ed, Hospital de Santo António, Porto.

Julien, H. (2013). La vie de la SFMC Le mot du président Médecine de catastrophe et devoir de transmission, la Lettre de la Société Française de Médecine de Catastrophe SFMC, № 73:2-3.

Kelly, J. D, Shandera, W. X. (2016). Viral \& Rickettsial Infections. In: Papadakis MA, McPhee S J (eds) Current Medical Diagnosis \& Treatment, $55^{\text {th }}$ ed, cap 32, McGraw-Hill, New York.

Oliveira, J. (2015). Abordagem da infecção por Acinetobacter. In: Aragão I, Vasconcelos C (eds) Manual Prático de Utilização de Anti-Infecciosos, $2^{\mathrm{a}}$ ed, Hospital de Santo António, Porto.

Philip, S. (2016). Spirochetal Infections. In: Papadakis MA, McPhee S J (eds) Current Medical Diagnosis \& Treatment, $55^{\text {th }}$ ed, cap 33, McGraw-Hill, New York.

Savio, C., Coste-Savio, S. (2015). Reportage Ebola: une mission particulière en Afrique de l'Ouest, la Lettre de la Société Française de Médecine de Catastrophe SFMC, No $83: 20-21$.

Schwartz, B. S. (2016). Bacterial \& Chlamydial Infections. In: Papadakis MA, McPhee S J (eds) Current Medical Diagnosis \& Treatment, 55th ed, cap 33, McGraw-Hill, New York.
Sikorski, J., Swerhun, P,. Lawrie, C., Macpate, F. (2012). Public Services Health and Safety Association (PSHSA) Protecting HealthCare Workers from Infectious Diseases: A Self-Assessment Tool, Toronto.

CENTERS FOR DISEASE CONTROL AND PREVENTION (CDC). Healthcare-associated Infections (HAls), Diseases and Organisms in Healthcare Settings (http: / / www.cdc.gov/HAl/organisms/ organisms.html, acedido em 2016-04-09).

Decreto Regulamentar n. ${ }^{\circ} 76 / 2007$, que actualiza o Decreto Regulamentar 6/2001 do Ministério do Trabalho e da Solidariedade (http: / / www.portaldasaude.pt/NR/ rdonlyres/AF267FFC-1E51-41DC-8736D52019BCAB6F/0/0449904543.pdf acedido em 2016-04-07).

DIRECÇÃO GERAL DE SAÚDE - Orientação no 013/2015 de 13/11/2015 Doença por vírus Ébola. Procedimentos perante uma exposição acidental, (www.dgs.pt acedido em 2016-04-04).

OCCUPATIONAL SAFETY \& HEALTH ADMINISTRATION - OSHA (2016a) ( h t t p s : / / w w w. osha.gov / SLT C / emergencypreparedness/index.html).

OCCUPATIONAL SAFETY \& HEALTH ADMINISTRATION - OSHA (2016 b) (https://www.osha.gov/dcsp/products/ topics/incidentinvestigation/index.html).

ORGANIZAÇÃO MUNDIAL DE SAÚDE - OMS (2016 a). Influenza update - 260 de 04 April 2016 (http://www. who.int/influenza/surveillance_monitoring/ updates/latest_update_GIP_surveillance/en/).

ORGANIZAÇÃO MUNDIAL DE SAÚDE (2016 b). Influenza at the Human-Animal Interface (HAI) (www.who. int/influenza/human_animal_interface/en acedido em 2016-04-11).

ORGANIZAÇÃO MUNDIAL DE SAÚDE (2016 c). Proyecto de Estrategia Mundial del Sector de la Salud contra el VIH para 2016-2021 (http://www.who.int/ hiv/strategy2016-2021/GHSS_HIV_SP_06012016. pdf?ua=1. acedido em 2016-04-11).

SIEM (2013). Versão 2.0, $1^{\text {a }}$ ed, INEM Lisboa (http://www.inem.pt/ files/2/documentos/20140108162916460041.pdf). 

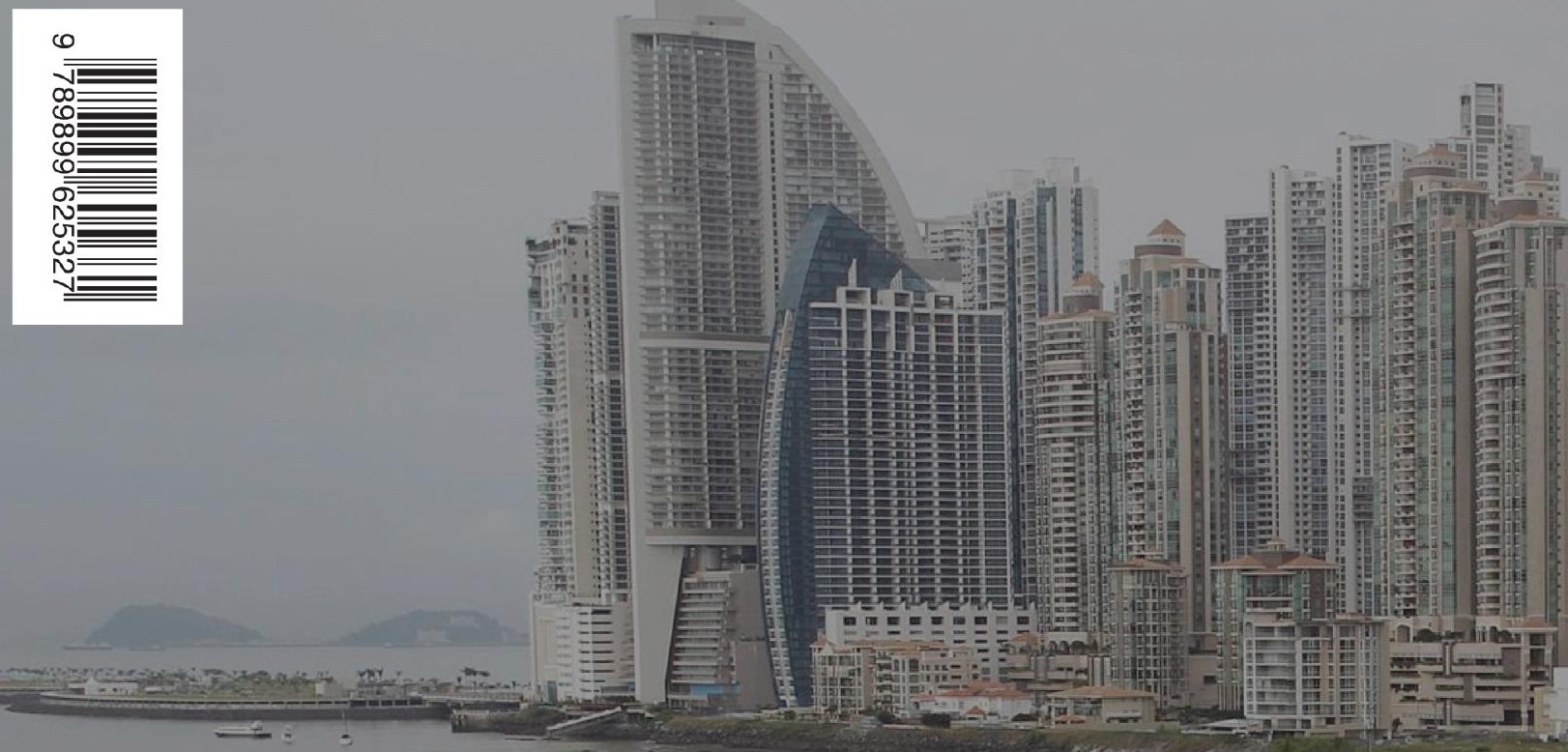

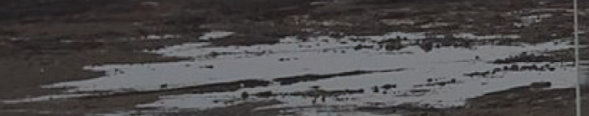

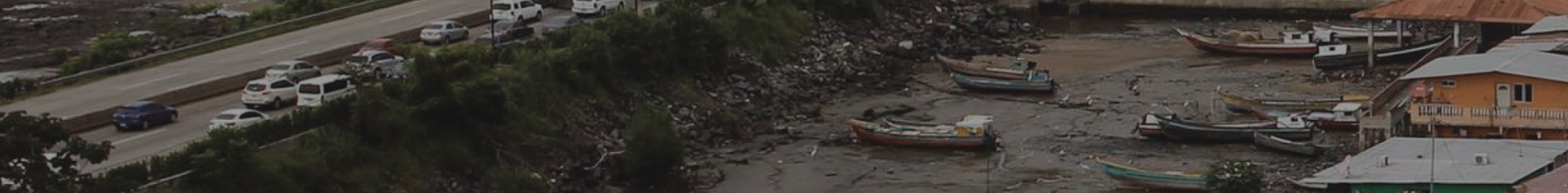

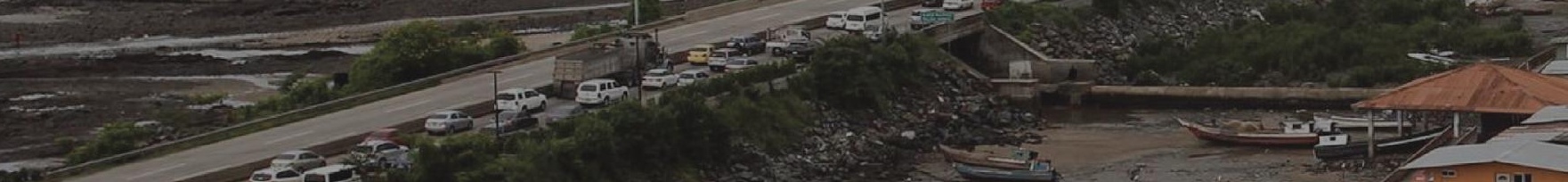
inse- $n=$ Riscos I I I

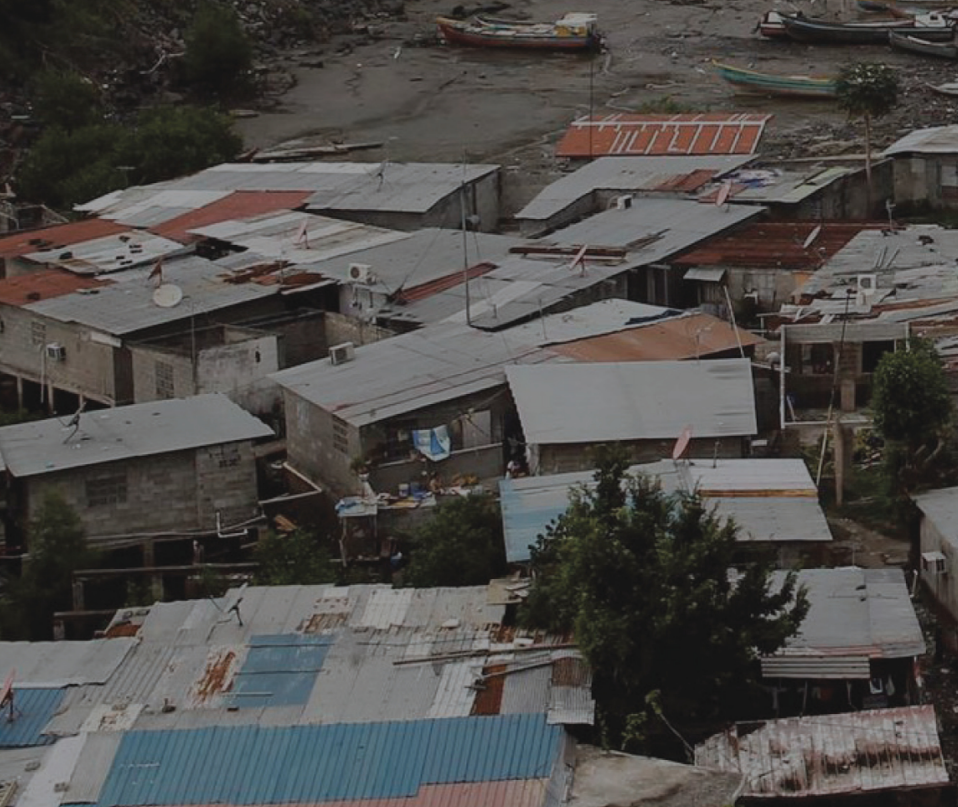

